\title{
Electric properties of olive oil under pressure
}

\author{
L. T. Pawlicki ${ }^{1}$ • R. M. Siegoczyński ${ }^{1}$-S. Ptasznik ${ }^{2} \cdot$ K. Marszałek $^{2}$
}

Received: 12 February 2021 / Revised: 15 April 2021 / Accepted: 17 April 2021 / Published online: 7 May 2021

(c) The Author(s) 2021

\begin{abstract}
The main purpose of the experiment was a thermodynamic research with use of the electric methods chosen. The substance examined was olive oil. The paper presents the resistance, capacitive reactance, relative permittivity and resistivity of olive. Compression was applied with two mean velocities up to $450 \mathrm{MPa}$. The results were shown as functions of pressure and time and depicted on the impedance phase diagram. The three first order phase transitions have been detected. All the changes in material parameters were observed during phase transitions. The material parameters measured turned out to be the much more sensitive long-time phase transition factors than temperature. The values of material parameters and their dependence on pressure and time were compared with the molecular structure, arrangement of molecules and interactions between them. Knowledge about olive oil parameters change with pressure and its phase transitions is very important for olive oil production and conservation.
\end{abstract}

Keywords Olive oil $\cdot$ Triglyceride $\cdot$ Pressure $\cdot$ Temperature $\cdot$ Capacitance $\cdot$ Resistance $\cdot$ Reactance $\cdot$ Dissipation factor . Phase transition $\cdot$ Resistivity $\cdot$ Permittivity

\section{Introduction}

Olive oil is a mixture of triglycerides (general triolein) with little addition of fatty acids. Triglycerides have molecules combined with the main glycerin part which is a source of electric dipole field and three chains of fatty acid radicals. The mutual position of molecules and their chains and olive oil composition have greater influence on the mechanical and electric parameters of the substance, which can be seen in earlier works on diacylglycerols [1-3], triacylglycerols (triglycerides) [4-7], sunflower oil [8, 9], soy oil [9], rapeseed oils [10, 11], castor oil [5] and olive oil [8, 12, 13]. The content of triglyceride mixture determines many long-time phase transitions in olive oil. Some basic transitions detected in the work have been shown in Fig. 1.

These crystal forms and photos correlated can be seen in some earlier works [14-16].

$\triangle$ L. T. Pawlicki

leszek.pawlicki@pw.edu.pl

1 Faculty of Physics, Warsaw University of Technology, ul. Koszykowa 75, 00-622 Warsaw, Poland

2 Institute of Agricultural and Food Biotechnology, ul. Rakowiecka 36, 02-532 Warsaw, Poland
There are three types of interactions between molecules of quasi-neutral fluids such as triglycerides and their mixtures such as olive oil: dipolar, induced and dispersion. The last one is characteristic for every particle interaction, even for inert gases. For molecules which either have or do not have very small permanent electric dipole momentum like triglycerides, this dispersion mechanism can describe relations between parts and phase transitions of the substance examined [17].

The main parameter of phase transition detection is temperature, but in the long-time transitions compression hitting is very weak and it is going out of the chamber before temperature value difference takes over uncertainty. This makes detection of phase transition temperature change very hard. Electric parameters are much more sensitive, which will be shown in this work.

Pressure is used to make olive oil by squeezing olives and for high-pressure olive oil conservation (high pressure kills microorganisms). In both cases, change of olive oil parameters can be dangerous for used machines. For example, phase transition from liquid to solid rapidly change compressibility and viscosity. This phenomena can cause press breaking or pipe clogging. 


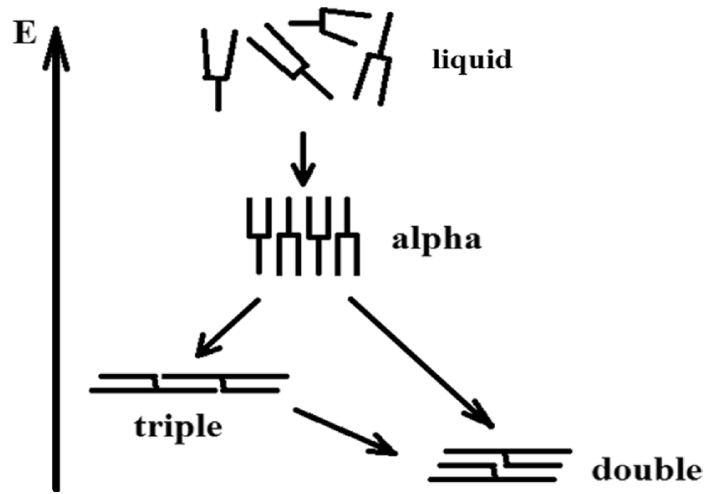

Fig. 1 Basic triglyceride mixture phase transition diagram

\section{Substance examined}

The substance examined in this experiment was $21(1) \mathrm{cm}^{3}$ olive oil with triglyceride composition, which can be seen in Table 1.

\section{Measurement}

In this experiment, time, pressure, capacitance, dissipation factor and temperature were directly measured. All the information measured was digitally saved on laboratory computer. The data were taken by specially prepared computer program which measured time directly. The records were saved every $3 \mathrm{~s}$. Pressure was introduced by $17 \mathrm{~mm}$ diameter piston from the hand press to the cylindrical grounded steel chamber. In the first part of the experiment pressure was introduced by steps by two compression mean speeds $v_{m 1}=253.1(3) \frac{\mathrm{MPa}}{\mathrm{h}}$ and $v_{m 2}=122.1(1) \frac{\mathrm{MPa}}{\mathrm{m}}$ up to $450 \mathrm{MPa}$. After compression with $v_{m 2}=122.1(1) \frac{\mathrm{MPa}}{\mathrm{h}}$ research set has been left for $5.5 \mathrm{~h}$ on maximum pressure. Temperature was measured by a thermocouple. Pressure was measured by special manganin coil whose resistance is rising with the rising pressure. Capacitance and dissipation factors were measured by $35.0(1) \mathrm{mm}$ long cylindrical capacitor with $11.8(1) \mathrm{mm}$ and $12.8(1) \mathrm{mm}$ diameter covers, with six $3 \mathrm{~mm}$ diameter holes on each cover on RLC bridge with $1 \mathrm{kHz}$ frequency. Electric values in this experiment were measured with the use of alternating current, so every other source of electromagnetic field outside the chamber could have had influence on it. That is why Faraday cage effect was used in metal chamber grounding. Temperature measurement was done with $0.1{ }^{\circ} \mathrm{C}$ precision, but the uncertainty was assumed on $1{ }^{\circ} \mathrm{C}$ because of the pressure introduction method used which was a source of additional hit and temperature noise. Pressure induction by steps was used because this method gives more time for thermodynamic equilibrium to be achieved and makes compression mean speed control easier and their uncertainty lower. For the sake of clarity, the uncertainties were shown on figures only when the number of points of each curve was low.

\section{Results and discussion}

Molecules are setting their positions to reach minimum value of electric potential. This ordering creates more space between molecules, which decreases interactions and pressure. Next, electric dipoles are canceling each other which is a normal phenomenon for double crystal form, so interactions between molecules construction are weaker and spaces between them are collapsing. In this experiment, we can observe the three first order phase transitions shown in Figs. 2, 3, 4, 5 and 6:

- in Figs. 2 and 3 and in Figs. 4 and 5 between sections $A$ and $B$ as the space between the point of inflection of relative permittivity function and the maximum point of resistivity function and first maximum on temperature curve and selected point in Fig. 6. It can be seen at $p=232(14) \mathrm{MPa}$ and $T=23(1){ }^{\circ} \mathrm{C}$. It should be a transition between liquid and crystal alpha phase as shown in Fig. 1. This transition takes long time, and the temperature change shown in Fig. 4 is very weak and near temperature uncertainty, so it is hardly detectable. But if we use relative permittivity, resistivity (shown in Figs. 2, 3 and 5) or reactance (shown in Fig. 6), we can record it easily,

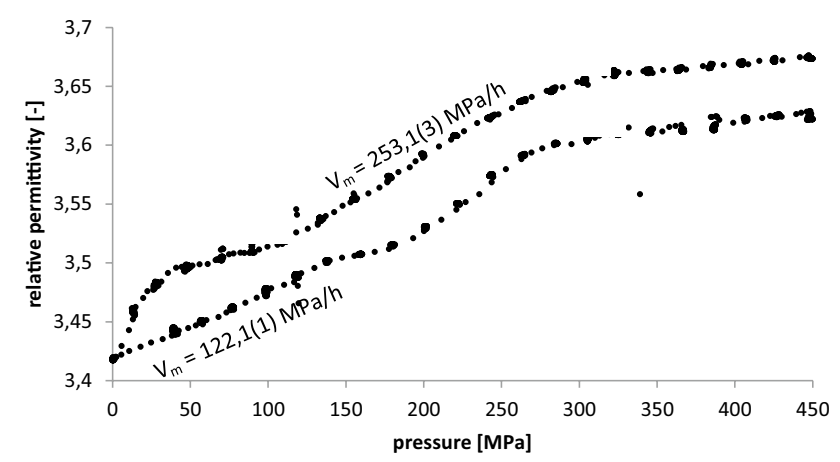

Fig. 2 Permittivity as a function of pressure
Table 1 Molecular composition of olive

\begin{tabular}{llllllllllll}
\hline Content [\%] & 76.8 & 11.2 & 5.9 & 3.4 & 1 & 0.7 & 0.4 & 0.3 & 0.1 & 0.1 & 0.1 \\
\hline Fatty acid & $\mathrm{C} 18: 1$ & $\mathrm{C} 16: 0$ & $\mathrm{C} 18: 2$ & $\mathrm{C} 18: 0$ & $\mathrm{C} 16: 1$ & $\mathrm{C} 18: 3$ & $\mathrm{C} 20: 0$ & $\mathrm{C} 20: 1$ & $\mathrm{C} 17: 0$ & $\mathrm{C} 17: 1$ & $\mathrm{C} 22: 0$ \\
\hline
\end{tabular}




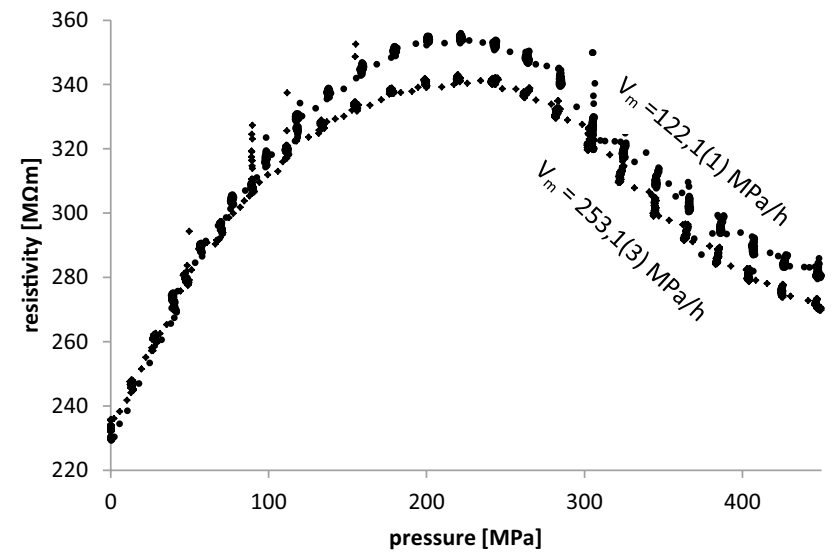

Fig. 3 Resistivity as a function of pressure

- in Fig. 5 between sections C and D as a point of temperature curve second maximum shown in Fig. 4 and selected point in Fig. 6. It can be seen at $p=444(10) \mathrm{MPa}$ and $T=23(1){ }^{\circ} \mathrm{C}$ after maximum (450 MPa) pressure has been set. It should be a partial transition between crystal alpha and triple phase shown in Fig. 1,
- in Fig. 5 between sections D and $\mathrm{E}$ as a point of inflection of relative permittivity, resistivity and compressibility functions. It can be seen at $p=440(10) \mathrm{MPa}$ and $T=23(1){ }^{\circ} \mathrm{C}$ after maximum (450 MPa) pressure has been set. It should be a transition between crystal alpha and triple to double phase shown in Fig. 1.

The molecular concentration variations inducted by pressure have direct influence on relative permittivity. Triglyceride molecule can be described by electric dipole. The increasing concentration of dipoles triggers relative permittivity rise, which can be seen in Figs. 2 and 5, section A and $\mathrm{B}$. The opposite situation can be seen in section $\mathrm{D}$, but in this case the main trigger is dipole cancelation. Similar relative permittivity curves for other triglyceride compositions can be seen in some earlier works ([9] soy oil, [10,11] rape-seed oil).

The main way of electric alternating current conduction in olive oil is molecular dipoles rotation. The liquid parts ordering and phase transitions to alpha and triple forms make some free spaces. This process makes dipoles rotation easier, so capacitive reactance has to go down, which can be seen in Fig. 6. The third phase transition to double
Fig. 4 Temperature as a function of time $\left(v_{m 2}=122.1(1) \frac{\mathrm{MPa}}{\mathrm{h}}\right)$
Fig. 5 Comparison of material factors functions $\left(v_{m 2}=122.1(1) \frac{\mathrm{MPa}}{\mathrm{h}}\right)$
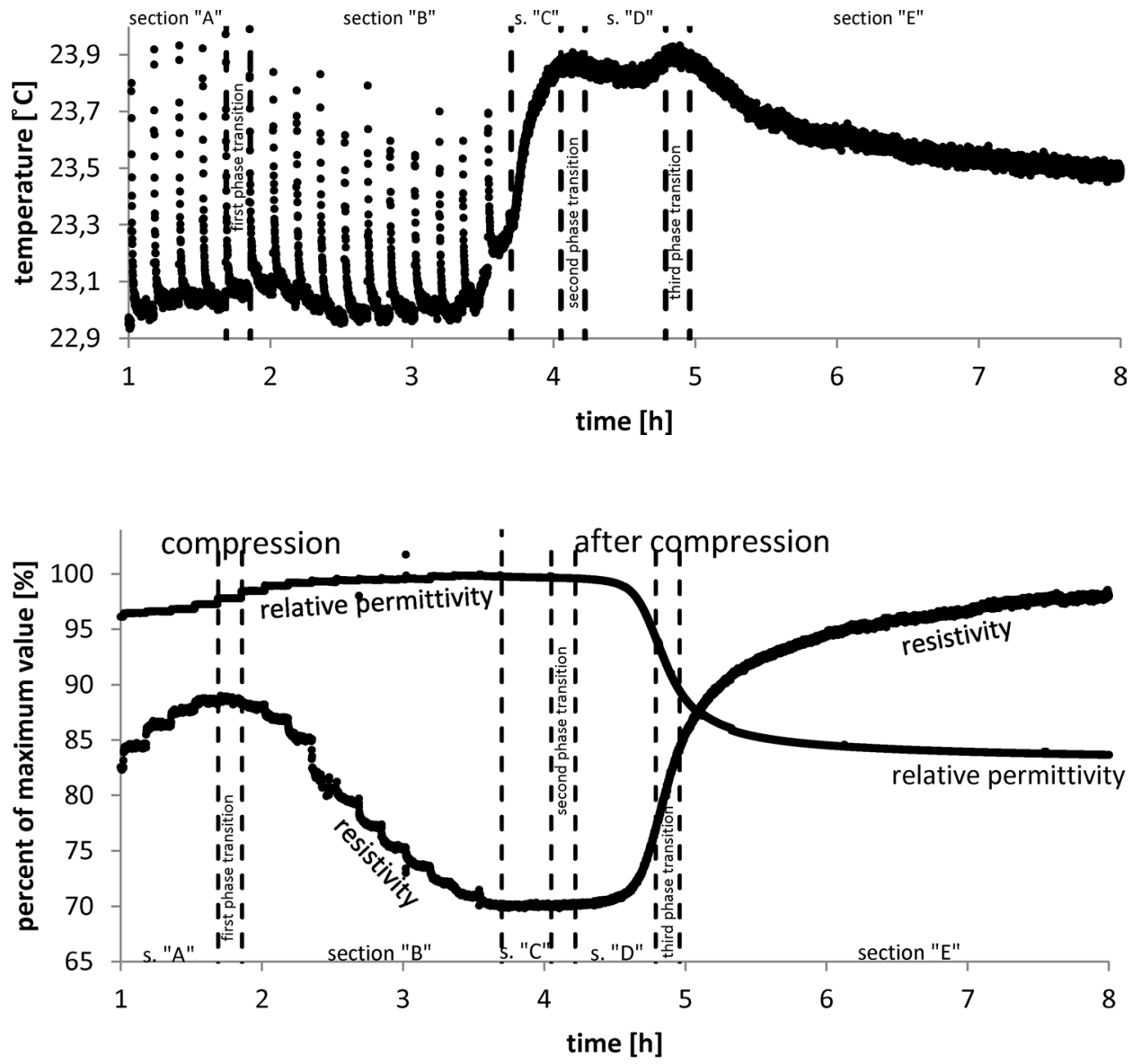
Fig. 6 Impedance phase diagram $\left(v_{m 2}=122.1(1) \frac{\mathrm{MPa}}{\mathrm{h}}\right)$

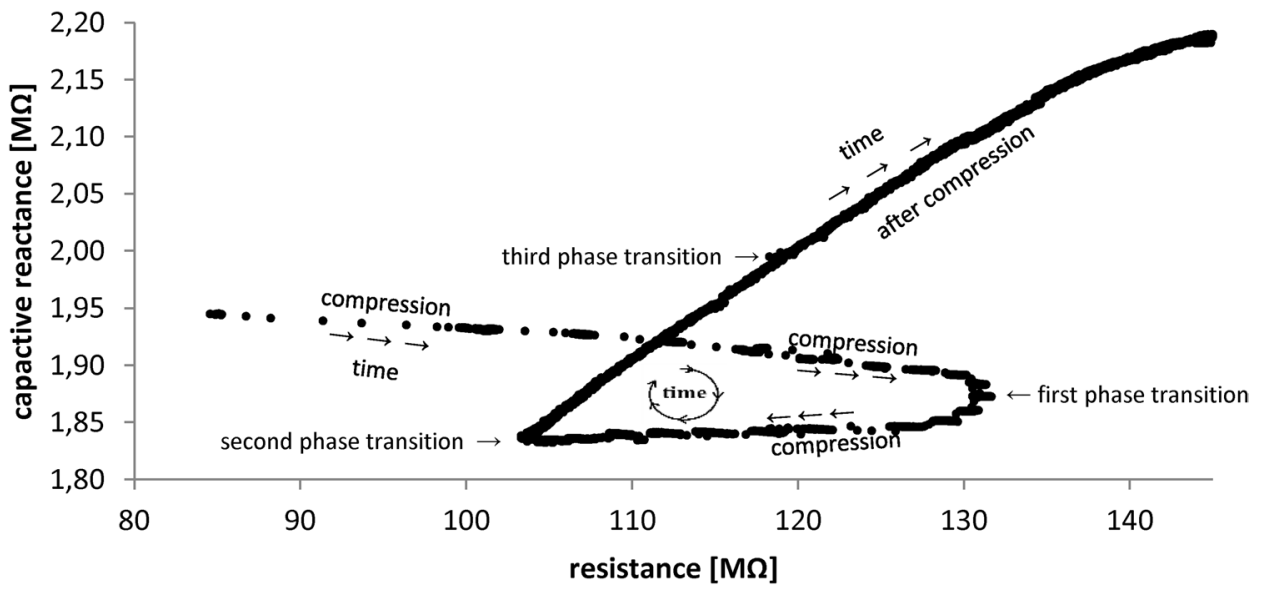

form shown in Fig. 1 causes electric dipole canceling and a similar effect as in the case when dipoles concentration goes down and capacitive reactance rises higher than on the beginning with zero pressure.

The main way of electric direct current conduction in olive oil is ionic transport. There is a small number of ions, probably from fatty acids, so resistance is high and olive is still a very strong dielectric material. Ions need some free space channels to move. Molecule of triglyceride have three long carbon chains which can fit other molecular chains. This process makes ion transport harder, because chains close ionic channels. The rising pressure makes molecules closer and their chains fit better, so resistivity has to rise (first part of Fig. 3 and section A of Fig. 5 up to $232 \mathrm{MPa}$ ). Compression continuation over $232 \mathrm{MPa}$ makes deformation of triglyceride molecular form to alpha crystal phase which makes some space between molecules and makes ionic transport easier with every new alpha crystal. It can be seen in the second part of Figs. 3 and 5 in section $\mathrm{B}$ as resistivity decreases. In section $\mathrm{C}$ and $\mathrm{D}$ situation is stabilizing. Between these two sections, a part of alpha crystals is evaluating to triple phase crystal form shown in Fig. 1, and even if pressure was increasing, the new ion channels between triple crystals are still stable; therefore, resistivity is stable. Between sections D and E triple and the rest of alpha phase is changing to double phase crystal form shown in Fig. 1. Most of free ion channel spaces are collapsing by pressure and in section E resistivity is rising much more than ever earlier in this experiment.

As can be seen in Figs. 2 and 3, compression speed has some influence on phase transition and crystallization processes. First, faster compression leaves less time for compression heat to escape leading to local temperature and pressure rising as well as faster crystallization, which can result in faster decrease of resistance. Second, the greater speed of compression leaves less time for making some after-transition spaces. These two processes together result in higher concentration of electric molecular dipoles and faster increase of permittivity.

\section{Conclusions}

In the study, the three long-time phase transitions have been detected. Also, transformation processes were discussed and explained. The main parameter of phase transition detection is temperature, but in long-time transitions compression hitting is very weak and it is going out of the chamber before temperature value difference takes over uncertainty. This makes detection of phase transition very hard. Electric parameters considered in this work turned out to be much more sensitive than temperature. Parameters of olive oil are changing with pressure and phase transitions sometimes very rapidly. Pressure is used for production and conservation of olive of oil. So, for protection of machines there should be made some sensors to control process. As I have shown in this paper electric sensors could be great in this case and this technology would be simple to apply.

\section{Declarations}

Conflict of Interest We do not have any conflicts of interest

Compliance with Ethics Requirements The examined substance was olive oil which is common substance and it is not dangerous. This work was made by researching only inanimate things. Than none ethical consideration have to be done.

Open Access This article is licensed under a Creative Commons Attribution 4.0 International License, which permits use, sharing, adaptation, distribution and reproduction in any medium or format, as long as you give appropriate credit to the original author(s) and the source, provide a link to the Creative Commons licence, and indicate if changes were made. The images or other third party material in this article are included in the article's Creative Commons licence, unless indicated otherwise in a credit line to the material. If material is not included in 
the article's Creative Commons licence and your intended use is not permitted by statutory regulation or exceeds the permitted use, you will need to obtain permission directly from the copyright holder. To view a copy of this licence, visit http://creativecommons.org/licenses/by/4.0/.

\section{References}

1. Rostocki AJ, Malanowski A, Tarakowski R, Szlachta K, Kiełczyński P, Szalewski M, Balcerzak A, Ptasznik S (2013) The sound velocity measurement in diacylglycerol oil under high pressure. High Press Res 33:172-177

2. Malanowski A, Rostocki AJ, Kiełczyński P, Szalewski M, Balcerzak A, Kościesza R, Tarakowski R, Ptasznik S, Siegoczyński RM (2013) Viscosity and compressibility of diacylglycerol under high pressure. High Press Res 33:178-183

3. Kiełczyński P, Szalewski M, Balcerzak A, Malanowski A, Siegoczyński RM, Ptasznik S (2012) Investigation of high-pressure phase transitions in DAG (diacylglycerol) oil using the Bleustein-Gulyaev ultrasonic wave method. Food Res Int 49:60-64

4. Rostocki AJ, Tefelski DB, Wieja K (2011) The equation of state of triolein up to $1 \mathrm{GPa}$. High Press Res 31:168-171

5. Rostocki AJ, Tefelski DB, Ptasznik S (2009) Compressibility studies of some vegetable oils up to $1 \mathrm{GPa}$. High Press Res 29:721-725

6. Kos A, Tefelski DB, Kościesza R, Rostocki AJ, Roszkiewicz A, Ejchart W, Jastrzębski C, Siegoczyński RM (2007) Certain physico-chemical properties of triolein and methyl alcohol- triolein mixture under pressure. High Press Res 27:39-42

7. Tefelski DB, Rostocki AJ, Kos A, Kościesza R, Siegoczyński RM (2007) Pressure induced volume changes in triolein with addition of methyl alcohol. High Press Res 27:57-61

8. Guignon B, Aparicio C, Sanz PD (2009) Volumetric properties of sunflower and olive oils at temperatures between 15 and $55^{\circ} \mathrm{C}$ under pressures up to $350 \mathrm{MPa}$. High Press Res 29:38-45
9. Rostocki AJ, Kościesza R, Tefelski DB, Kos A, Siegoczyński RM, Chruściński $€$ (2007) Pressure-induced phase transition in soy oil. High Press Res 27:43-46

10. Kościesza R, Rostocki AJ, Kos A, Tefelski DB, Siegoczyński RM, Zych $€$ (2007) Observation of pressure-induced phase transitions in rapeseed oil with methyl alcohol mixtures. High Press Res 27:51-55

11. Rostocki AJ, Wiśniewski R, Wilczyńska T (2007) High pressure phase transition in rape-seed oil. J Mol Liq 135:120-122

12. Tarakowski R, Malanowski A, Kościesza R, Siegoczyński RM (2014) VIS spectroscopy and pressure induced phase transitionschasing the olive oils quality. J of Food Engin 122:28-32

13. Rostocki AJ, Tarakowski R, Kiełczyński P, Szalewski M, Balcerzak A, Ptasznik S (2013) The ultrasonic investigation of phase transition in olive of oil up to $0.7 \mathrm{GPa}$. J Am Oil Chem Soc 90:813-818

14. Akita Ch, Kawaguchi T, Kaneko F (2006) Structural study on polymorphism of cis-unsaturated triacylglycerol: triolein. J Phys Chem B 110:4346-4353

15. Hollander FF, Boerrigter SXM, van de Streek J, Bennema P, Meekes H, Yano J, Sato K (2003) Comparing the morphology of $\beta$-n.n.n. with $\beta$ '-n.n+2.n and $\beta$ '-n.n.n-2 triacylglycerol crystals. J Phys Chem B 107:5680-5689

16. Sato K (2001) Crystallization behaviour of fats and lipids - a rev. Chem Eng Sc 56:2255-2265

17. McClellan AL (1963) Tables of experimental dipole moments. W. H. Freeman, San Francisco

Publisher's Note Springer Nature remains neutral with regard to jurisdictional claims in published maps and institutional affiliations. 